\title{
Original Article \\ Radon Concentrations and their Controlling Factors in Mud-built Houses in Dong Van Plateau Karst Geopark, Ha Giang Province
}

\author{
Nguyen Thuy Duong ${ }^{1, *}$, Nguyen Anh Nguyet ${ }^{1}$, Nguyen Van Huong ${ }^{1}$, \\ Jan Schimmelmann ${ }^{2}$, Nguyen Dinh Thai ${ }^{1}$, Arndt Schimmelmann ${ }^{3}$ \\ ${ }^{1}$ VNU University of Science, Vietnam National University, Hanoi, 334 Nguyen Trai, Hanoi, Vietnam \\ ${ }^{2}$ University of Bremen, Institute of Geography, Celsiusstrasse FVG-M, D-28359 Bremen, Germany \\ ${ }^{3}$ Indiana University, Department of Earth and Atmospheric Sciences, 1001 East 10th Street, Bloomington, \\ Indiana 47405-1405, USA
}

Received 30 January 2020

Revised 05 March 2020; Accepted 12 March 2020

\begin{abstract}
This article presents results of radon $\left({ }^{222} \mathrm{Rn}\right)$ and thoron $\left({ }^{220} \mathrm{Rn}\right)$ concentrations in room air measured inside mud-built houses that are traditional dwellings on the Dong Van Karst Plateau. The measurements were conducted in December 2016 and July 2017, corresponding to "cold" and "warm" months, respectively, by using a portable RAD7 detector. Our results show that ${ }^{222} \mathrm{Rn}$ and ${ }^{220} \mathrm{Rn}$ concentrations were elevated during the "warm" month and the concentrations of ${ }^{220} \mathrm{Rn}$ were always higher than the respective ${ }^{222} \mathrm{Rn}$ values at the same measured locations during the two months. The relatively long half-life of ${ }^{222} \mathrm{Rn}$ (3.83 days) causes efficient dispersion and loss from room air due to air ventilation. In contrast, the much shorter half-life of ${ }^{220} \mathrm{Rn}(55.6$ seconds) results in elevated radiation near mud surfaces prior to attenuation into room air further away from walls and floors. Average concentrations of ${ }^{220} \mathrm{Rn}$ in room air during both "cold" and "warm" months are much higher than in normal outside air $\left(\sim 10 \mathrm{~Bq} \mathrm{~m}^{-3}\right)$. The severely elevated concentrations of ${ }^{220} \mathrm{Rn}$ in room air of mud-built homes are likely harmful to human occupants, especially to those sleeping near mud-walls.
\end{abstract}

Keywords: Radiation, radon gas, ${ }^{222} \mathrm{Rn},{ }^{220} \mathrm{Rn}$, temperature, air ventilation.

\footnotetext{
* Corresponding author.

E-mail address: duongnt_minerals@vnu.edu.vn 


\title{
Nồng độ khí radon trong nhà trình tường và các yếu tố ảnh hưởng, lấy ví dụ ở khu vực Cao Nguyên Đá Đồng Văn, tỉnh Hà Giang
}

\author{
Nguyễn Thùy Dương ${ }^{1, *}$, Nguyễn Ánh Nguyệt ${ }^{1}$, Nguyễn Văn Hướng ${ }^{1}$, \\ Jan Schimmelmann ${ }^{2}$, Nguyễn Đình Thái ${ }^{1}$, Arndt Schimmelmann ${ }^{3}$ \\ ${ }^{I}$ Truờng Đại học Khoa học Tự nhiên, Đại học Quốc gia Hà Nội, 334 Nguyễn Trãi, Hà Nội, Việt Nam \\ ${ }^{2}$ University of Bremen, Institute of Geography, Celsiusstrasse FVG-M, D-28359 Bremen, Germany \\ ${ }^{3}$ Indiana University, Department of Earth and Atmospheric Sciences, 1001 East 10th Street, Bloomington, \\ Indiana 47405-1405, USA \\ Nhận ngày 30 tháng 01 năm 2020 \\ Chỉnh sửa ngày 05 tháng 3 năm 2020; Chấp nhận đăng ngày 12 tháng 3 năm 2020
}

\begin{abstract}
Tóm tắt: Bài viết trình bày kết quả nghiên cứu về nồng độ khí radon $\left({ }^{222} \mathrm{Rn}\right.$ và $\left.{ }^{220} \mathrm{Rn}\right)$ và các yếu tố ảnh hưởng bên trong nhà trình tường, một loại nhà truyền thống ở Cao Nguyên Đá Đồng Văn. Nồng độ khí radon được đo trong tháng 12/2016 và tháng 7/2017, tiêu biểu cho tháng "lạnh" và tháng "nóng" trong năm, bằng thiết bị cầm tay RAD7. Kết quả cho thấy nồng độ khí radon có xu hướng tăng cao vào tháng "nóng" và nồng độ đồng vị ${ }^{220} \mathrm{Rn}$ luôn cao hơn ${ }^{222} \mathrm{Rn}$ tại cùng thời điểm và vị trí khảo sát bất kể tháng "nóng" hay "lạnh". Đồng vị ${ }^{222} \mathrm{Rn}$ có chu kỳ bán rã đủ lớn $(3,83$ ngày) để có thể khuyếch tán trong không khí nhờ sự lưu thông không khí, trong khi ${ }^{220} \mathrm{Rn}$ có chu kỳ bán rã ngắn hơn rất nhiều (55,6 giây) nên đã làm tăng cao nồng độ của đồng vị này tại gần nguồn phát trước khi nó có thể bị suy giảm nhanh trong môi trường không khí. Nồng độ trung bình của ${ }^{220} \mathrm{Rn}$ trong cả tháng "lạnh" và "nóng" đều cao hơn rất nhiều giá trị trung bình nồng độ ${ }^{220} \mathrm{Rn}$ trong môi trường không khí $\left(\sim 10 \mathrm{~Bq} \mathrm{~m}^{-3}\right)$. Với nồng độ cao như vậy, bức xạ phóng xạ trực tiếp từ ${ }^{220} \mathrm{Rn}$ có thể là mối nguy hiểm đối với người dân sinh sống trong nhà trình tường không thể bỏ qua, đặc biệt là khi người dân có thói quen kê giường ngủ sát góc tường.
\end{abstract}

Tù khóa: khí radon, ${ }^{222} \mathrm{Rn},{ }^{220} \mathrm{Rn}$, nhiệt độ, lưu thông không khí.

\footnotetext{
* Tác giả liên hệ.

Địa chỉ email: duongnt_minerals@vnu.edu.vn

https://doi.org/10.25073/2588-1094/vnuees.4547
} 


\section{Mở đầu}

Radon là khí hiếm phóng xạ, không màu, không mùi, không vị với 3 đồng vị phóng xạ chính gồm ${ }^{222} \mathrm{Rn}$ (radon, chu kỳ bán rã 3,83 ngày), ${ }^{220} \mathrm{Rn}$ (thoron, chu kỳ bán rã 55,6 giây) và ${ }^{219} \mathrm{Rn}$ (actinon, chu kỳ bán rã 3,96 giây) tương ứng là sản phẩm trung gian của các dãy phân rã phóng xạ urani $\left({ }^{238} \mathrm{U}\right)$, thori $\left({ }^{232} \mathrm{Th}\right)$ và plutoni $\left({ }^{239} \mathrm{Pu}\right)$ (Hình 1). Chúng có mặt chủ yếu trong thành phần của đá, đất và các loại vật liệu xây dựng. Trong các nghiên cứu về đồng vị phóng xạ radon, actinon $\left({ }^{219} \mathrm{Rn}\right)$ thường được bỏ qua do thời gian tồn tại quá ngắn, ít có khả năng tác động đến con người. Các đồng vị radon xuất hiện từ các dãy đồng vị phóng xạ và trú ngụ trong các vật liệu tự nhiên, có thể đi vào không khí, tích lũy với nồng độ cao trong môi trường kín (ví dụ như nhà ở, hầm lò và hang động) và có nguy cơ gây phơi nhiễm phóng xạ đối với con người [1]. Cho đến nay, khí radon trong môi trường nhà ở được ước tính chiếm khoảng trên $50 \%$ năng lượng phóng xạ có nguồn gốc tự nhiên và nhân tạo ảnh hưởng đến cơ thể sống $[2,3]$.

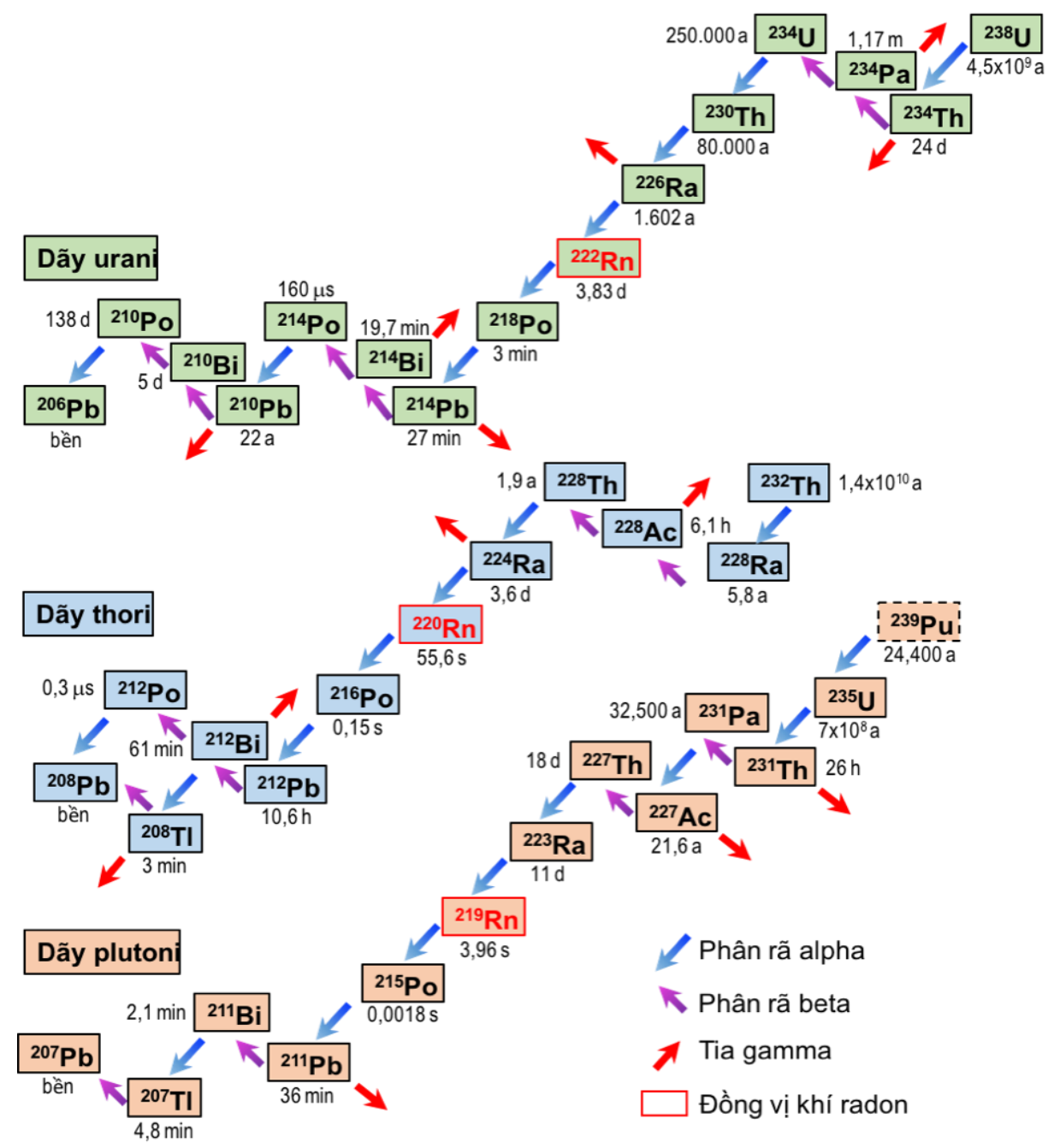

Hình 1 . So đồ các dãy phân rã phóng xạ từ urani $\left({ }^{238} \mathrm{U}\right)$, thori $\left({ }^{232} \mathrm{Th}\right)$ và plutoni $\left({ }^{239} \mathrm{Pu}\right)$. Các đồng vị tương ứng được hình thành sau mỗi chu kỳ bán rã tính theo thời gian năm (a), ngày (d), giờ (h), phút (min), giây (s) và micro giây ( $\mu$ s) (Nguồn: Hiệp hội Hạt nhân Thế giới - WNA). 
Khí radon trong nhà bắt nguồn chủ yếu từ các khe nứt nền địa chất bên dưới hoặc từ các lỗ rỗng của vật liệu xây dựng, do đó nồng độ radon trong nhà cao nhất có thể tập trung nhiều trong tầng hầm hoặc tầng trệt, nơi ít có sự lưu thông không khí. Có nhiều yếu tố ảnh hưởng đến sự phát xạ và nồng độ khí radon trong nhà như đặc điểm vật liệu xây dựng, đặc điểm thời tiết (độ ẩm, nhiệt độ, áp suất,...) giữa không khí trong nhà và ngoài trời [1,4-6]. Radon có thể tồn tại, phát tán trong không khí và đi vào phổi, máu và bạch huyết qua đường hô hấp. Tại đó, sự phân rã của các đồng vị radon tạo ra sản phẩm trung gian là các đồng vị phóng xạ kim loại như poloni (Po) và bismuth $(\mathrm{Bi})$, đi kèm là các hạt alpha và tia gamma (Hình 1). Các sản phẩm kim loại phóng xạ trung gian này được hấp thụ mạnh mẽ vào các hạt bụi và các son khí, có thể tồn tại lâu trong không khí. Trong quá trình hô hấp, chúng có thể đi vào cơ thể con người, lắng đọng trên các biểu mô của phổi, sau đó tiếp tục tác động đến các tế bào phế quản và tế bào bài tiết, đây chính là nguyên nhân gây ra ung thư phổi. Do đó, cơ thể sống bị phơi nhiễm khí radon ở nồng độ cao có thể phát sinh các bệnh lý nghiêm trọng $[2,3]$.

Nồng độ khí radon cao đã được phát hiện tồn tại trong các nhà có kiến trúc tương tự nhà trình tường (xây dựng trực tiếp bằng đất tự nhiên) ở một số nơi trên thế giới như Trung Quốc, Ấn Độ, Đức, Nhật $[7,8]$. Ở Việt Nam, đồng vị ${ }^{220} \mathrm{Rn}$ đã được xác định ở ngưỡng rất cao, gấp trên 20 lần nồng độ trung bình trong không khí trên bề mặt trái đất, trong kiểu nhà trình tường truyền thống của đồng bào dân tộc sinh sống ở Cao nguyên đá Đồng Văn [9]. Đây là loại nhà có chi phí xây dựng thấp, vật liệu làm nhà chủ yếu từ đất giàu sét tại địa phương. Với đặc điểm là tường và nền nhà đều được nén trực tiếp bằng đất, khí radon có thể phát xạ trực tiếp vào môi trường không khí trong nhà thông qua các lỗ hổng và khe nứt xuất hiện trên bề mặt tường và nền nhà đất. Trong nhà trình tường, hệ thống khe nứt của tường đất, sự lưu thông không khí trong nhà là các yếu tố có thể ảnh hưởng lớn đến sự khuếch tán và phân bố của radon vào không khí. Những cư dân sinh sống trong kiểu nhà trình tường thường không nhận biết và phát hiện được rủi ro phóng xạ này. Bài viết được thực hiện nhằm nghiên cứu nồng độ khí radon trong nhà trình tường và một số yếu tố ảnh hưởng tới sự phân bố đó.

\section{2. Đối tượng và phương pháp}

\subsection{Nhà trình tường ở khu vục Cao nguyên đá Đồng Văn, tỉnh Hà Giang}

Nghiên cứu đã lựa chọn một ngôi nhà trình tường truyền thống, tiêu biểu của đồng bào dân tộc sinh sống ở Cao nguyên đá Đồng Văn để thực hiện các thí nghiệm. Nhà trình tường được khảo sát của một gia đình người Nùng, ở thôn Coóc Choóng, xã Bạch Đích, huyện Yên Minh, tỉnh Hà Giang. Ngôi nhà được xây dựng bằng cách đầm và nén đất giàu sét tại địa phương dựng thành các bức tường dày $(\sim 60 \mathrm{~cm})$ và nền nhà (Hình 2). Tùy theo từng địa phương và đồng bào, nhà trình tường có thể to nhỏ khác nhau, nhưng chúng đều có chung kiểu kiến trúc là nhà ba gian, có một cửa chính ở gian giữa, một cửa phụ ở một trong hai gian hai bên, hai cửa sổ (Hình $2, \mathrm{~A}$ và $B$ ) và có cấu trúc đối xứng (Hình $2, C$ và $D)$. Bên trong nhà, khu vực ngủ thường nằm đối xứng nhau ở 2 góc tường của 2 gian bên và thường được ngăn cách với khu vực sinh hoạt chung bằng các vách gỗ mỏng hoặc các rèm vải.

\subsection{Phương pháp xác định nồng độ khí radon}

Khí radon trong nghiên cứu này, gồm đồng vị ${ }^{222} \mathrm{Rn}$ và ${ }^{220} \mathrm{Rn}$, được xác định trong môi trường không khí nhà trình tường bằng thiết bị cầm tay $\mathrm{RAD} 7$ vào tháng 12/2016 và tháng 7/2017, tiêu biểu cho tháng "lạnh" và tháng "nóng" trong năm ở khu vực nghiên cứu [10]. Không khí được hút vào thiết bị RAD7 qua một ống nhựa, đi qua một màng lọc (bề dày tương ứng 1,0 $\mu \mathrm{m}$ ) và hộp hút ẩm chứa hạt silica nhằm loại bỏ bụi và hơi nước trong không khí. RAD7 định lượng các hạt alpha trong quá trình bán rã các đồng vị radon theo từng chu kỳ 10 phút, ở chế độ sniff mode [11]. Không khí trong nhà cho các phép đo đều được thu ở độ cao $\sim 40 \mathrm{~cm}$ so với nền nhà, tương ứng với chiều cao của giường 
ngủ và tầm cao của mũi người dân hô hấp khi sinh hoạt trong nhà. Thói quen của người dân là ngồi xổm hoặc ngồi trực tiếp dưới nền khi nấu ăn và ăn cơm.

Quy trình khảo sát được thực hiện tại các vị trí trong nhà theo mạng lưới gồm khu vực sinh hoạt chung (Hình 2C) và khu vực ngủ (giường ngủ) (Hình 2D) với khoảng cách các điểm đo $1 \mathrm{~m}$. Dựa vào cấu trúc đối xứng của nhà trình tường, sơ đồ khảo sát chỉ thực hiện ở nửa nhà đại diện cho khu vực sinh hoạt chung và khu vực ngủ. Các phép đo được lặp lại ít nhất tại mỗi vị trí khảo sát 3 lần nhằm đánh giá độ chính xác của số liệu. Giá trị nồng độ của các đồng vị radon tại mỗi vị trí khảo sát là trung bình cộng của các phép đo lặp lại. Độ chính xác của thiết bị RAD7 đã được thiết lập vào năm 2016 bằng cách so sánh số liệu đồng vị ${ }^{222} \mathrm{Rn}$ và ${ }^{220} \mathrm{Rn}$ đo được của RAD7 và SARAD ${ }^{\circledR}$ RTM2200, trong đó SARAD $^{\circledR}$ RTM2200 đã được hiệu chuẩn ở một số nhà trình tường khu vực miền Bắc Việt Nam.

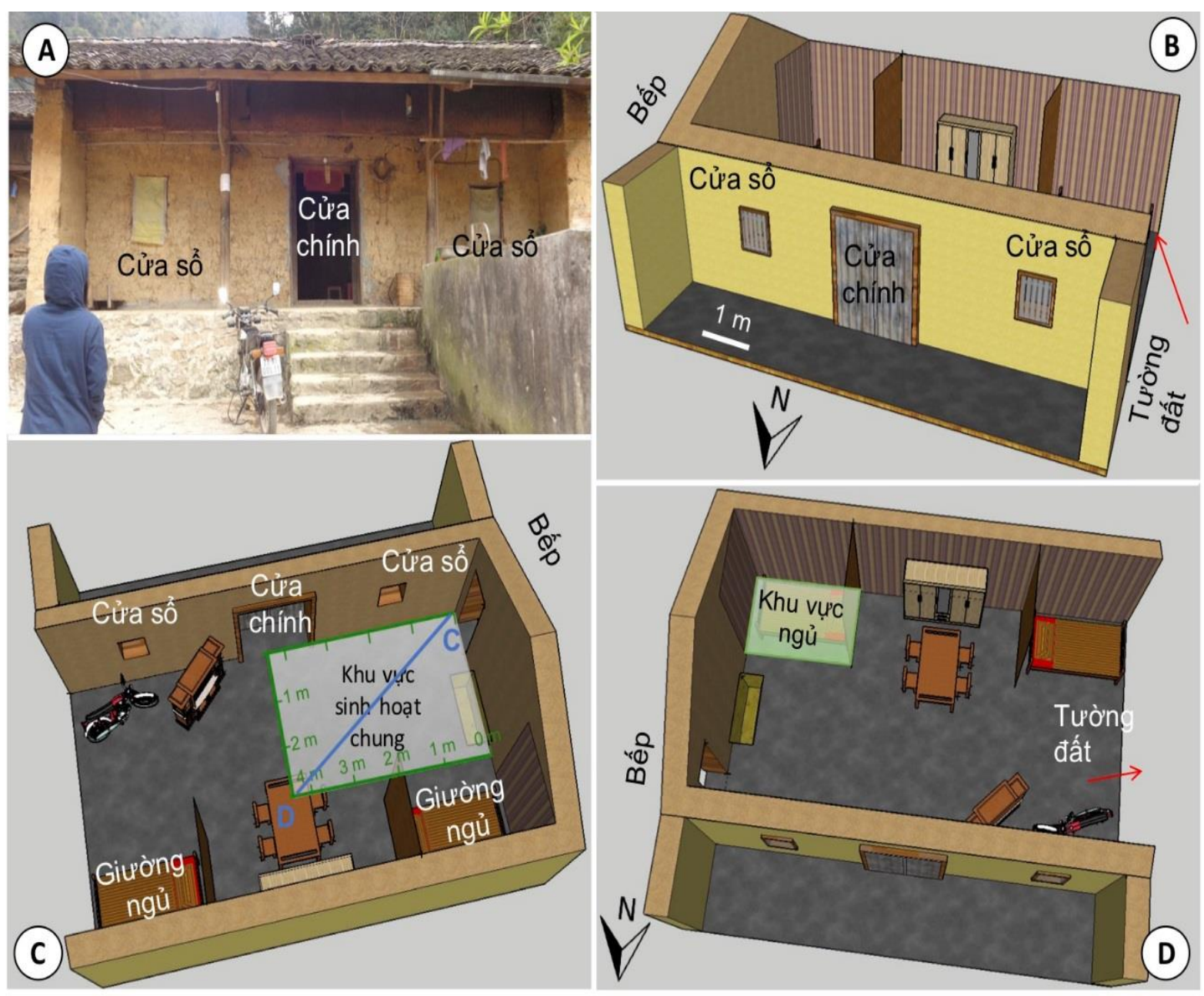

Hình 2. Nhà trình tường $(A)$ và mô hình nhà trình tường $(B, C, D)$ [9] khảo sát 12/2016 và 7/2017 bằng thiết bị đo hiện trường RAD7. Khu vực khảo sát trong nhà được tô màu màu xanh lá nhạt gồm khu vực sinh hoạt chung $(\mathrm{C})$ và khu vực ngủ $(\mathrm{D})$. Các điểm khảo sát thực hiện theo mạng lưới với khoảng cách 1m. 


\section{Kết quả và thảo luận}

\subsection{Nồng độ khí radon trong nhà trình tương}

Nồng độ khí radon $\left({ }^{222} \mathrm{Rn}\right.$ và $\left.{ }^{220} \mathrm{Rn}\right)$ trong môi trường không khí nhà trình tường được thể hiện trong Bảng 1 bao gồm các giá trị nhỏ nhất, lớn nhất và trung bình của các điểm đo khu vực sinh hoạt chung và khu vực ngủ, theo các tháng khảo sát tương ứng. Tại các điểm khảo sát, nồng độ trung bình của ${ }^{220} \mathrm{Rn}$ luôn có giá trị cao hơn trung bình nồng độ ${ }^{222} \mathrm{Rn}$. Nồng độ ${ }^{222} \mathrm{Rn}$ tại khu vực sinh hoạt chung trong tháng "lạnh" và "nóng" đều $<100 \mathrm{~Bq} \mathrm{~m}^{-3}$, tương ứng với mức trung bình của ${ }^{222} \mathrm{Rn}$ trong môi trường không khí nói chung [2]. Riêng tại khu vực ngủ, trung bình nồng độ ${ }^{222} \mathrm{Rn}$ trong tháng "nóng" lại có giá trị > $100 \mathrm{~Bq} \mathrm{~m}^{-3}$ (Hình 3A).

Bảng 1. Nồng độ ${ }^{222} \mathrm{Rn}$ (radon) và ${ }^{220} \mathrm{Rn}$ (thoron) $\left(\mathrm{Bq} \mathrm{m}^{-3}\right)$ trong môi trường không khí nhà trình tường theo tháng "lạnh" và "nóng" (n là số điểm đo tại từng khu vực; Nhiệt độ trung bình tại trạm quan trắc Hà Giang của tháng 12/2016 (tháng "lạnh") và 7/2017 (tháng "nóng") được xác định theo Niên giám thống kê 2018 của Cục thống kê tỉnh Hà Giang (2019) [10]

\begin{tabular}{|c|c|c|c|c|c|c|c|c|}
\hline \multirow{3}{*}{$\begin{array}{l}\text { Giá trị nồng } \\
\text { độ khí radon } \\
\left(\mathrm{Bq} \mathrm{m}^{-3}\right)\end{array}$} & \multicolumn{4}{|c|}{ Tháng "lạnh" $(12 / 2016)-18,6^{\circ} \mathrm{C}$} & \multicolumn{4}{|c|}{ Tháng "nóng" $(7 / 2017)-27,6^{\circ} \mathrm{C}$} \\
\hline & \multicolumn{2}{|c|}{$\begin{array}{l}\text { Khu vực sinh hoạt chung } \\
(\mathrm{n}=20)\end{array}$} & \multicolumn{2}{|c|}{$\begin{array}{c}\text { Khu vực ngủ } \\
(\mathrm{n}=3)\end{array}$} & \multicolumn{2}{|c|}{$\begin{array}{l}\text { Khu vực sinh hoạt chung } \\
(\mathrm{n}=24)\end{array}$} & \multicolumn{2}{|c|}{$\begin{array}{c}\text { Khu vực ngủ } \\
(\mathrm{n}=3)\end{array}$} \\
\hline & ${ }^{222} \mathrm{Rn}$ & ${ }^{220} \mathrm{Rn}$ & ${ }^{222} \mathrm{Rn}$ & ${ }^{220} \mathrm{Rn}$ & ${ }^{222} \mathrm{Rn}$ & ${ }^{220} \mathrm{Rn}$ & ${ }^{222} \mathrm{Rn}$ & ${ }^{220} \mathrm{Rn}$ \\
\hline Nhỏ & 5 & 128 & 23 & 976 & 18 & 89 & 215 & 231 \\
\hline Lớn & 96 & 793 & 43 & 1137 & 116 & 2030 & 285 & 2475 \\
\hline 1 rui & 43 & 456 & 33 & 1034 & 77 & 563 & 241 & 1514 \\
\hline Sai số & 26 & 187 & 10 & 89 & 32 & 537 & 38 & 1156 \\
\hline
\end{tabular}
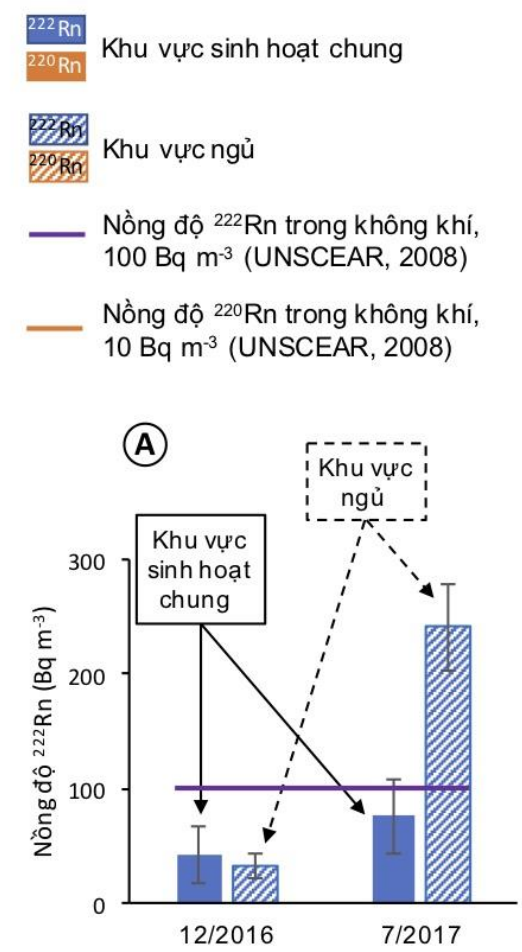

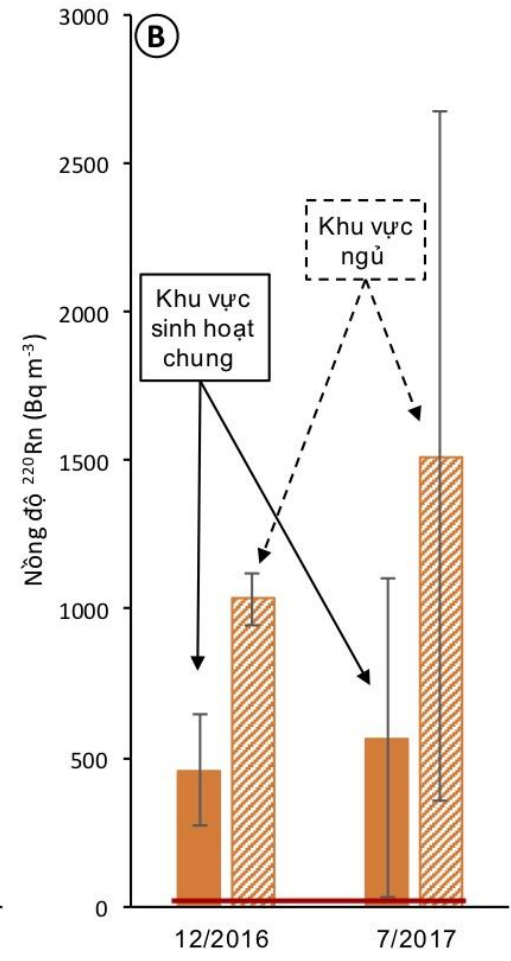

Hình 3. Nồng độ trung bình ${ }^{222} \mathrm{Rn}$ (màu xanh) và ${ }^{220} \mathrm{Rn}$ (màu da cam) trong nhà trình tường tại khu vực sinh hoạt chung và khu vực ngủ theo tháng "lạnh" (12/2016) và tháng "nóng" (7/2017). 
Nồng độ ${ }^{220} \mathrm{Rn}$ trong không khí nhà trình tường đều ở mức rất cao so với mức trung bình của ${ }^{220} \mathrm{Rn}$ trong môi trường không khí nói chung là $10 \mathrm{~Bq} \mathrm{~m}^{-3}$ [2]. Cụ thể, nồng độ ${ }^{220} \mathrm{Rn}$ tại khu vực sinh hoạt chung và khu vực ngủ, tương ứng, cao gấp 45-56 lần và 100-150 lần mức trung bình chung (Hình 3B). Đồng vị ${ }^{220} \mathrm{Rn}$ có chu kỳ bán rã ngắn (55,6 giây) đã từng bị bỏ qua khi xem xét tác động của khí radon trong môi trường không khí đến sức khỏe của con người [8]. Tuy nhiên, với mức năng lượng $6,29 \mathrm{MeV}$ phát ra cho mỗi đồng vị ${ }^{220} \mathrm{Rn}$ phân rã, tổng mức năng lượng cơ thể sống tiếp nhận là rất lớn nếu bị phơi nhiễm trong môi trường không khí có nồng độ ${ }^{220} \mathrm{Rn}$ cao [2]. Cho đến nay, chưa có ngưỡng an toàn về mức nồng độ ${ }^{220}$ Rn trong không khí như đối với đồng vị ${ }^{222} \mathrm{Rn}$, nhưng có ngưỡng an toàn về mức phơi nhiễm khí phóng xạ trong không khí, thể hiện bằng giá trị liều chiếu trong khoảng thời gian bị phơi nhiễm [12].

Người dân sinh sống trong nhà trình tường có thói quen kê giường ngủ sát tường. Khu vực ngủ thường ở góc giữa hai tường đất và được quây kín, ngăn cách với khu vực sinh hoạt chung bằng rèm vải hoặc miếng gỗ mỏng (Hình $2 \mathrm{D}$ ). Kết quả khảo sát cho thấy nồng độ ${ }^{220} \mathrm{Rn}$ trung bình ở khu vực ngủ cao hơn khu vực sinh hoạt chung 2-2,5 lần. Như vậy, có thể thấy cư dân có khả năng bị phơi nhiễm đồng vị ${ }^{220} \mathrm{Rn}$ cao nhất khi ngủ và đây dường như cũng là thời gian dài nhất cư dân ở trong nhà mỗi ngày (8 giờ so với tổng số 13 giờ cư dân ở trong nhà).

\subsection{Các yếu tố ảnh hưởng đến nồng độ khí radon trong nhà trình twờng}

a) Đặc điểm và sự phân bố của ${ }^{222} R n$ và ${ }^{220} R n$

Như đã đề cập ở trên, tường đất và nền nhà được nén trực tiếp từ đất tại chỗ trong kiểu nhà trình tường được coi như nguồn lưu giữ các đồng vị mẹ của khí radon [9]. Theo đường chéo $\mathrm{CD}$ (Hình $2 \mathrm{C}$ ), từ góc giữa 2 tường đất đến giữa nhà, nồng độ ${ }^{222} \mathrm{Rn}$ phân bố không theo quy luật và gần như không có sự thay đổi đáng kể giữa những điểm gần tường đất và không gian giữa nhà (Hình 4A), bất kể tháng "lạnh" hay "nóng". Trong khi đó, nồng độ ${ }^{220} \mathrm{Rn}$ có xu hướng giảm mạnh từ sát góc giữa 2 tường đất đến giữa nhà (Hình 4B). Theo đường $\mathrm{CD}$ (Hình 2C), ở vị trí cách góc giữa 2 tường đất $~ 1,3-1,7 \mathrm{~m}$ nồng độ ${ }^{220} \mathrm{Rn}$ giảm nhanh xuống còn $17-20 \%$ so với giá trị nồng độ tại vị trí góc giữa 2 tường, và không có sự biến động nhiều đến giữa nhà (Hình $4 \mathrm{~B})$. Trong không khí nhà trình tường, ${ }^{220} \mathrm{Rn}$ có nồng độ cao đến rất cao ở các vị trí gần tường đất, giảm mạnh ở các vị trí xa tường đất, như ở giữa nhà.
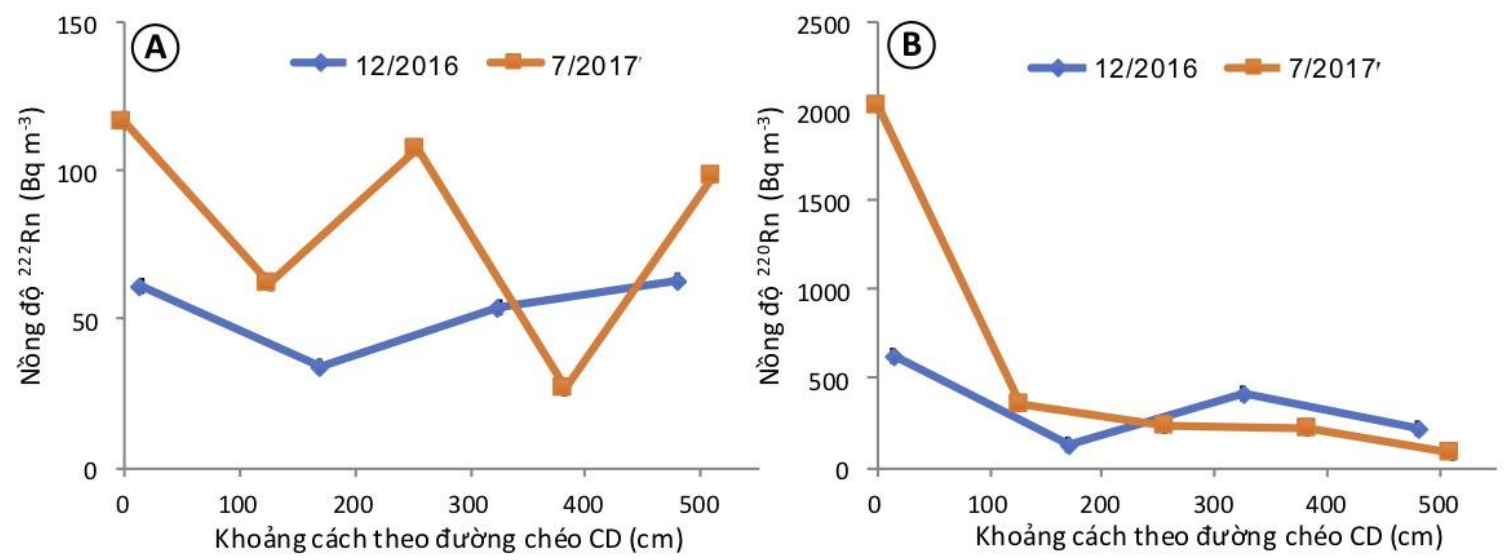

Hình 4. Phân bố nồng độ ${ }^{222} \mathrm{Rn}(\mathrm{A})$ và ${ }^{220} \mathrm{Rn}(\mathrm{B})$ theo đường chéo $\mathrm{CD}$ (từ góc giữa 2 tường đất đến giữa phòng) trong tháng "lạnh" (12/2016) và tháng "nóng” (7/2017). 
Sự phân bố của khí radon từ nguồn phát chịu ảnh hưởng từ đặc điểm chu kỳ bán rã của các đồng vị. Đồng vị ${ }^{222} \mathrm{Rn}$ có chu kỳ bán rã dài $(3,83$ ngày) cho phép ${ }^{222} \mathrm{Rn}$ có đủ thời gian để có thể trao đổi với không khí bên ngoài trong quá trình khuếch tán vào không khí trong nhà trước khi xảy ra quá trình phân rã. Do đó, nồng độ ${ }^{222} \mathrm{Rn}$ phân bố không có quy luật từ góc giữa hai tường đất đến giữa phòng (Hình 4A). Ngược lại, đồng vị ${ }^{220} \mathrm{Rn}$ với chu kỳ bán rã ngắn (55,6 giây) thường bị phân rã ngay sau khi được khuếch tán vào không khí trong nhà, trước khi có cơ hội trao đổi với không khí bên ngoài. Chính vì đặc điểm này nên nồng độ ${ }^{220} \mathrm{Rn}$ giảm nhanh ở những vị trí xa tường đất (Hình $4 \mathrm{~B})$. Quá trình diễn ra tương tự nếu cơ thể sống hít thở không khí có tồn tại khí radon (gồm ${ }^{222} \mathrm{Rn}$ và ${ }^{220} \mathrm{Rn}$ ), ${ }^{222} \mathrm{Rn}$ trong không khí đi vào đường hô hấp vẫn có khả năng thoát ra bên ngoài cơ thể sống qua nhịp thở tiếp theo, trong khi ${ }^{220} \mathrm{Rn}$ gần như bị giữ lại hoàn toàn nếu bị xâm nhập vào hệ hô hấp.

\section{b) Điêu kiện nhiẹt độ}

Nồng độ khí radon được khảo sát lặp lại theo mạng lưới nhà trình tường trong tháng "lạnh" và tháng "nóng", tương ứng với nhiệt độ trung bình 18,6 và $27,6^{\circ} \mathrm{C}[10]$, cho thấy có sự khác nhau và biến thiên tỷ lệ với nhiệt độ (Hình 5). Nồng độ trung bình của ${ }^{222} \mathrm{Rn}$ và ${ }^{220} \mathrm{Rn}$ ở khu vực sinh hoạt chung và khu vực ngủ đều thấp hơn vào tháng "lạnh" và cao hơn vào tháng "nóng".

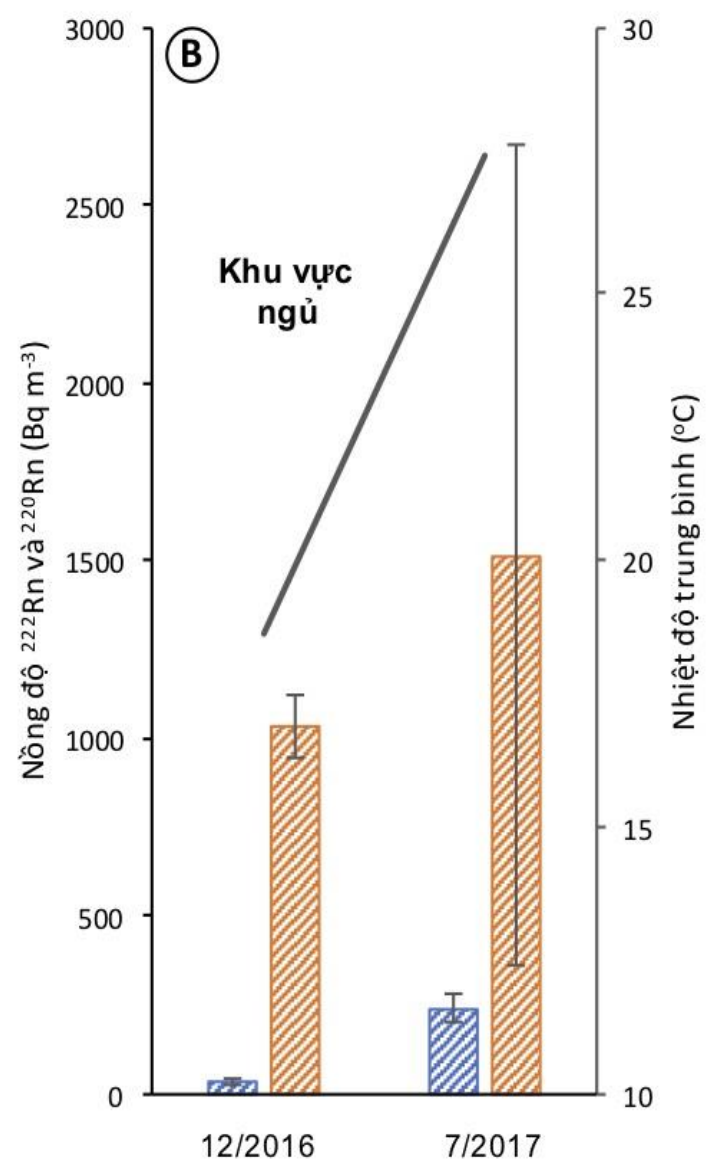

Hình 5. Mối tương quan giữa nồng độ khí radon $\left({ }^{222} \mathrm{Rn}\right.$ và $\left.{ }^{220} \mathrm{Rn}\right)$ trong không khí nhà trình tường và nhiệt độ. (A) Khu vực sinh hoạt chung; (B) Khu vực ngủ. 
Nồng độ ${ }^{222}$ Rn tại khu vực sinh hoạt chung và khu vực ngủ đều $<100 \mathrm{~Bq} \mathrm{~m}{ }^{-3}$ ở tháng "lạnh", nhưng tại khu vực ngủ ở tháng "nóng" nồng độ ${ }^{222} \mathrm{Rn}$ tăng cao với giá trị $>100 \mathrm{~Bq} \mathrm{~m}^{-3}$. Nồng độ ${ }^{220} \mathrm{Rn}$ trong nhà trình tường luôn cao hơn mức trung bình trong không khí $\left(10 \mathrm{~Bq} \mathrm{~m}^{-3}\right)$ rất nhiều (Bảng 1), và tại khu vực ngủ ở tháng "nóng", nồng độ ${ }^{220} \mathrm{Rn}$ đặc biệt tăng mạnh, cao nhất đến hơn $2000 \mathrm{~Bq} \mathrm{~m}^{-3}$ ở điểm khảo sát ngay sát tường đất. Nguyên nhân là do trong điều kiện khí hậu gió mùa mùa hè với lượng mưa lớn, độ ẩm không khí cao làm độ ẩm của tường và sàn đất của nhà trình tường cũng tăng theo, và do đó làm tăng khả năng các đồng vị radon xâm nhập vào các lỗ hổng, khe nứt tồn tại trong tường và nền đất, từ đó có thể dễ dàng đi vào không khí trong nhà [13]. Hơn nữa, khi nhiệt độ tăng cao, động lực khuếch tán khí radon từ các lỗ rỗng trong tường và nền đất có xu hướng diễn ra nhanh hơn [4] làm cho nồng độ các đồng vị radon có giá trị cao ở các điểm đo gần hoặc sát tường.

\section{c) Mức độ trao đổi (luu thông) không khi}

Dựa vào đặc điểm chu kỳ bán rã của các đồng vị khí radon, mức độ lưu thông không khí có thể tác động lớn đến sự khuếch tán và di chuyển của chúng. ${ }^{222} \mathrm{Rn}$ có chu kỳ bán rã dài nên có thể phân tán nếu không khí có sự trao đổi, và có thể tích tụ nếu không khí ở trạng thái ngưng đọng. Tuy nhiên, ${ }^{220} \mathrm{Rn}$ với chu kỳ bán rã rất ngắn (55,6 giây) khó có thể di chuyển xa khỏi nguồn phát, và do đó khó khuếch tán đồng đều vào không khí, ngay cả khi có sự trao đổi không khí tốt. Như vậy, tác động của ${ }^{220} \mathrm{Rn}$ đến cư dân sinh sống trong nhà trình tường dường như nghiêm trọng hơn là của ${ }^{222} \mathrm{Rn}$.

Hơn nữa, sự phơi nhiễm khí phóng xạ radon còn nguy hiểm hơn vào thời điểm ban đêm, khi tất cả các cửa ra vào và cửa sổ đều được đóng kín, không khí gần như không có sự lưu thông, trong khi quá trình phân rã phóng xạ từ khí radon vẫn tiếp diễn liên tục từ tường đất và nền đất qua các khe nứt và lỗ hổng. Do vậy, giảm thiểu sự phơi nhiễm phóng xạ khí radon đối với cư dân cần xuất phát từ việc làm giảm nồng độ radon tích tụ trong nhà, đặc biệt là vào thời điểm ban đêm. Và một trong các biện pháp hữu hiệu là hạn chế sự khuếch tán khí radon từ nguồn phát vào không khí trong nhà bằng các biện pháp xử lý bề mặt tường và nền đất.

Kiến trúc của nhà trình tường thấp, có ít cửa sổ, cửa chính thấp do đó sự lưu thông không khí trong nhà trình tường kém. Nồng độ radon đo được trong nhà trình tường thay đổi khác nhau ở mỗi vị trí khác nhau trong nhà. Nồng độ khí radon ở các vị trí gần cửa sổ, cửa chính thường thấp hơn so với các vị trí khác. Điều này có thể được lý giải do khu vực gần cửa có sự lưu thông không khí tốt hơn, sự trao đổi khí giữa môi trường trong nhà và ngoài nhà diễn ra dễ dàng hơn [14]. Ở khu vực kín như khu vực ngủ, có hai mặt giáp tường đất, hai mặt còn lại được ngăn cách với khu vực sinh hoạt chung bằng vách gỗ mỏng hoặc rèm vài, không khí gần như tĩnh lặng, nồng độ khí radon đạt giá trị cao nhất với nồng độ ${ }^{222} \mathrm{Rn}>200 \mathrm{~Bq} \mathrm{~m}^{-3}$ và nồng độ ${ }^{220} \mathrm{Rn} \sim 1500 \mathrm{~Bq} \mathrm{~m}^{-3}$.

\section{Kết luận}

Khí phóng xạ radon trong môi trường không khí nhà trình tường khu vực Cao nguyên đá Đồng Văn có khả năng ảnh hưởng đến sức khỏe cư dân, đặc biệt trong tháng "nóng", khi mà nồng độ các đồng vị đều cao hơn mức độ trung bình của khí radon trong môi trường không khí nói chung. Nồng độ ${ }^{222} \mathrm{Rn}$ tại khu vực sinh hoạt chung và khu vực ngủ trong tháng "lạnh" thấp hơn $100 \mathrm{~Bq} \mathrm{~m}^{-3}$, và chỉ tăng cao hơn mức độ trung bình không khí nói chung tại khu vực ngủ trong tháng "nóng". Tuy nhiên, nồng độ ${ }^{220} \mathrm{Rn}$ cao hơn rất nhiều lần mức trung bình chung trong không khí nói chung, bất kể trong tháng "lạnh" hay "nóng". Kiến trúc nhà trình tường có mức độ lưu thông không khí kém cùng thói quen kê giường ngủ sát tường của cư dân dường như kéo gần sự tiếp xúc của cư dân đối với các bức xạ phóng xạ trực tiếp từ ${ }^{220} \mathrm{Rn}$. Kết quả nghiên cứu cho thấy cư dân sinh sống trong nhà trình tường thường xuyên phải tiếp xúc với khí phóng xạ có nồng độ cao, kể cả có sự trao đổi không khí tốt. Sự phát $x a{ }^{220} \mathrm{Rn}$ từ tường và nền đất là nguyên nhân chính, do đó cần có biện pháp ngăn ngừa sự phát tán này bằng phương pháp và vật liệu phù 
hợp. Hiện nay, Việt Nam chưa có điều tra dịch tễ học về ảnh hưởng của khí radon tới sức khỏe của người dân sống trong nhà trình tường.

\section{Lời cảm ơn}

Nghiên cứu được hoàn thành dưới sự hỗ trợ của Quỹ phát triển Khoa học và Công nghệ Quốc gia NAFOSTED (mã đề tài 105.99-2016.16). Thiết bị đo nồng độ khí radon cầm tay RAD7 được hỗ trợ của Viện Địa chất, Viện Hàn lâm Khoa học và Công nghệ Việt Nam; thiết bị

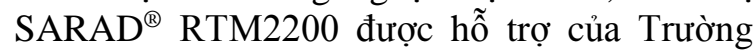
Đại học Indiana, Hoa Kỳ. Công tác khảo sát thực địa và đo đạc hiện trường tại nhà trình tường phục vụ nghiên cứu này nhận được sự giúp đỡ nhiệt tình từ bà Minh Ngọc Schimmelmann và ông Nùng Văn Minh. Tập thể tác giả trân trọng cảm ơn sự hỗ trợ và giúp đỡ kể trên.

\section{Tài liệu tham khảo}

[1] J. Gunn, Radon in caves, in: J. Gunn (Ed.), Encyclopedia of Caves and Karst Science, Fitzroy Dearborn, Taylor \& Francis Books, Inc., London, UK, 2003, pp. 617-619.

[2] The United Nations Scientific Committee on the Effects of Atomic Radiation (UNSCEAR), UNSCEAR 2008 Report to the General Assembly, with Scientific Annexes, in: Sources and Effects of Ionizing Radiation, vol. I, United Nations, New York, 2010.

[3] World Human Organization WHO, 2010. WHO Guidelines for Indoor Air Quality: Selected Pollutants. Geneva: World Health Organization, ISBN-13: 978-92-890-0213-4.

[4] V. Balek, I.N. Beckman, Theory of emanation thermal analysis XII - Modelling of radon diffusion release from disordered solids on heating, $\mathrm{J}$ Therm Anal Calorim 82 (2005) 755-759. https://doi.org/ 10.1007/s10973-005-0960-7.

[5] A. Sakoda, Y. Ishimori, K. Yamaoka, A comprehensive review of radon emanation measurements for mineral, rock, soil, mill tailing and fly ash, Appl Radiat Isotopes 69 (2011) 1422-1435. https://doi. org/ 10.1016/j.apradiso.2011.06.009.

[6] M. Schubert, A. Musolff, H. Weiss, Influences of meteorological parameters on indoor radon concentrations (222Rn) excluding the effects of forced ventilation and radon exhalation from soil and building materials, J Environ Radioactiv 192 (2018) 81-85. https://doi.org/10.1016/j.jenvrad. 2018.06.011.

[7] B. Shang, B. Chen, Y. Gao, Y.W. Wang, H.X. Cui, Z. Li, Thoron levels in traditional Chinese residential dwellings, Radiat Environ Biophys 44(3) (2005) 193-199. https://doi.org/10.1007/s00 411-005-0020-5.

[8] S. Gierl, O. Meisenberg, M. Wielunski, J. Tschiersch, An unattended device for high-voltage sampling of radon and thoron progeny, Rev Sci Instrum 85 (2014). https://doi.org/10.1063/1.486516.

[9] D. Nguyen-Thuy, H. Nguyen-Van, J. Schimmelmann, T.A.N. Nguyễn, K. Doiron, A. Schimmelmann, ${ }^{220} \mathrm{Rn}$ (Thoron) Geohazard in Room air of Earthen Dwellings in Vietnam, Geofluids, article ID 7202616, 11 pages, (2019). https://doi.org/10.1155 /2019/7202616.

[10] Ha Giang Statistics Office (GSO), Mean air temperature at Ha Giang station, in: Statistical Yearbook of Ha Giang 2018, Statistical Publishing House, Ha Giang, 2019, p. 24 (in Vietnamese).

[11] DURRIDGE Company, 2017. RAD7 Electronic Radon detector - user manual. Durridge, Radon Capture \& Analytics, Durridge Company Inc.

[12] The United Nations Scientific Committee on the Effects of Atomic Radiation (UNSCEAR), in: Sources, vol. I. United Nations, New York, 2000.

[13] M. Faheem, Matiullah, Radon exhalation and its dependence on moisture content from samples of soil and building materials, Radiat Meas 43(8) (2008) 1458-1462. https://doi.org/10.1016/j.radm eas.2008.02.023.

[14] W. Zhuo, T. Lida, S. Morizumi, Simulation of the concentration levels and distributions of indoor radon and thoron, Rad Prot Dosim 93 (2001) 357368. https://doi.org/10.1093/oxfordjournals.rpd.a0 06448 . 